\title{
Nitroso-Hemoglobin Preparation and Meat Product Colorant Development
}

\author{
Hammad HHM ${ }^{1 *}$, Meihu Ma1, Guofeng Jin ${ }^{1 *}$ and Lichao $\mathrm{He}^{2}$
}

${ }^{1}$ National R\&D Center for Egg Processing, College of Food Science and Technology, Huazhong Agricultural University, Wuhan, Hubei, PR China

${ }^{2}$ College of Food and Biotechnology, Wuhan Institute of Design and Science, Wuhan, Hubei, PR China

\begin{abstract}
Research focused on preparing new type curing pigment, which called Nitroso-hemoglobin prepared by use of by-products (beef blood), and its application prospect substitutes of nitrite, because of its a poisonous reagent, and can produce carcinogenic nitrosamine after reacting with amine and lead to carcinogenicity, nitrosamines toxicity in meet's product, and this project defined the development of the substitute of nitrite in the meat product from color to make meat color fixative with good stability and coloring stability, antioxidant, antimicrobials, increase nutrition value, and introduced as additives. Additionally, nitroso-hemoglobin pigment synthesis. Moreover, economic aids and environmental protection and its implementation possibility well developed.
\end{abstract}

Keywords: Nitrite; Hemoglobin; Meat by-products; Beef blood; Color development

\section{Introduction}

Hemoglobin is globular proteins (red blood cells) that ferry oxygen molecules and carbon dioxide molecules; all hemoglobin protein structure consists of four polypeptide subunits, which are held composed by hydrogen bonds, van der Waals forces, hydrophobic fundamental interactions, and ionic bonds, as well as four heme pigments, one in each of the subunits, heme groups contain positively-charged $\left(\mathrm{Fe}^{2+}\right)$ molecules reversibly bind to oxygen molecules and transport them to several areas within the body and release their oxygen loads; the complete hemoglobin undergoes conformational changes, which modified their affinity for oxygen [1-3]. Color is the most intimate characteristic indicator used by customers to judge meat freshness the color of meat may indicate microbial spoilage, but it is not the very good meter of nutritionary quality $[4,5]$. Color is the mainly consequential factor of meat quality products that significant influence's customer purchasing conclusion and materially affects their perception of the freshness of the product [6-8]. The effect color is very prominent clear to understanding troubles when they occur fresh and cured meat color both be contingent on myoglobin, but are substantially very distinctive from each other in terms of how they are successfully created and their comprehensive stability [9]. The first strong impression customers have of any meat commodity is its color and hence color is of furthermost importance and responsive; the color of meat could vary from the deep purplish-red of freshly cut beef to the light gray of faded cured beef [9]. Fortunately, everyone business practices with meat commodities must have a functioning comprehension about the color. Moreover, blood is a rich source of iron and proteins of high nutrition and functional quality [10]. Meats have great potential for delivering important nutrients such as antioxidants, minerals, dietary fiber fatty acids, and bioactive peptides into the diet $[11,12]$. However, to manufacture prosperous and quality products with these constituents, advanced technology's necessity be fully developed to significant. Increase their constancy and decrease their flavor impact on muscle foods. In addition, many regulatory hurdles must be overcome for the commercial production of meats with supplemented nutrients. These contain redefinition of high standard of identities and policies that allow front of the package nutritional claims [13]. Without these regulative modifications manufacture of healthier meat quality products won't come to be a fact since these products would not have a competitive benefit over unfortified meats [12].

Blood is incredibly a rich source of elevated nutritional values and functional high quality due to comprise iron and proteins. Consequently, blood used as food supplements and obtained products. It is occasionally mentioned by to as fluid protein [14,15]. Myoglobin is the main protein known as the control of meat pigment, although another hem protein such as cytochrome $\mathrm{C}$, and hemoglobin may also play important part in beef, lamb, poultry, and pork pigment [4]. Economic benefits and environmental protection can be both achieved by processing in meat color development, and this review paper discussed the progress in substitute of nitrite in meat produce from colorant, antioxidant, antioxidant, and antimicrobial [16]. Consumer's judge meat due to its color that is the most common quality indicator to use as freshness, fresh and cured meat depended on myoglobin, but are significantly different from each other in terms of by what method they are formed and their overall stability [17]. Our objectives were to review publish nitroso-hemoglobin preparation and meat product color development substitutes of nitrite in meet's product from color fixative, antioxidant, antimicrobials, increase nutrition value, and introduced as additives. Research conducted for raw meat pigment in under the last few years ago. The objective was there exactly indicated what is new but rather to talk over the present meat pigment study. As such, our valuation of new studied. Literature proposes that the subsequent was the key of interest to researchers. Nitrite is greatly used as the chromogenic reagent in meat product at present, because it can perform color in the meat product enchanting and prevent Clostridium botulinum in meat products. Nitrite is a toxic reagent and can yield carcinogenic nitrosamine after responding with amine. So, people are always looking for the substitutes of nitrite. This project looking to the development of the substitute of nitrite in the meat product from colorant, antioxidant and increase nutrition value. And suggestions in prospective furtherance meat product [18].

*Corresponding author: Guofeng Jin, National R\&D Center for Egg Processing, College of Food Science and Technology Huazhong Agricultura University, 1-Shizishan Street, Wuhan, Hubei 430070, PR China, Tel: +862787283177; E-mail: jgf@mail.hzau.edu.cn

Received January 17, 2017; Accepted February 06, 2017; Published February 13,2017

Citation: Hammad HHM, Meihu M, Guofeng J, Lichao H (2017) NitrosoHemoglobin Preparation and Meat Product Colorant Development. J Food Process Technol 8: 658. doi: 10.4172/2157-7110.1000658

Copyright: (c) 2017 Hammad HHM, et al. This is an open-access article distributed under the terms of the Creative Commons Attribution License, which permits unrestricted use, distribution, and reproduction in any medium, provided the original author and source are credited. 
Citation: Hammad HHM, Meihu M, Guofeng J, Lichao H (2017) Nitroso-Hemoglobin Preparation and Meat Product Colorant Development. J Food Process Technol 8: 658. doi: 10.4172/2157-7110.1000658

Page 2 of 8

\section{Title}

Preparation of $(\mathrm{Hb})$ imprinted polymer by $\mathrm{Hb}$ catalyzed ATRP and its application in biosensor.

Development and Application of the Substitute of Nitrite in the Meat Product

New type curing pigment glycosylation nitroso research progress of hemoglobin.

Influence of nitrosohaemoglobin with monascus on the color and

The research progress of nitrosohemoglobin pigment synthesis and its application

$(\mathrm{Hb})=$ hemoglobin

$(\mathrm{eATRP})=$ electrode by electrochemically mediated atom transfer radical Polymerization.

$(\mathrm{MIP})=$ Molecularly imprinted polymer

$(\mathrm{SAM})=$ Self-assembled monolayer

$(\mathrm{MAP})=$ Modified atmosphere packaging

\section{Results/Conclusion}

Displayed a broader linear range and a lower detection limit for hemoglobin $(\mathrm{Hb})$ determination when it was compared to those $\mathrm{Hb}$ sensors based on molecularly imprinted polymer (MIP) and in improve the polymer growth, mixed Self-assembled monolayer (SAM), Hb, and MIP was surface of electrode (MIP/Au).

Preparing new type curing pigment used as substitute of nitrite in the meat and meat product from colorant, antioxidant and antimicrobial which called Glycosylation nitroso - hemoglobin and its application and natural, pigment was treated with polysaccharide to prepare glycosylated nitroso - hemoglobin, stabilities and enhanced meat color

Preparing glycosylated nitroso-hemoglobin by the use of by-products (blood) in livestock and poultry processing and its application prospect were elaborated and used as curing pigment.

The using of nitroso-hemoglobin with monascuscolors had the ability to improve the quality of red sausage.

Nitroso-hemoglobin is used in meat processing to substitute of nitrite residue, improve the nutritional value of the meat product, synthesis and application of nitroso-hemoglobin and glycosylated nitroso- hemoglobin in meat products.

Table 1: Summary of research evaluating (Nitroso-hemoglobin preparation) and used in meat colorant development.

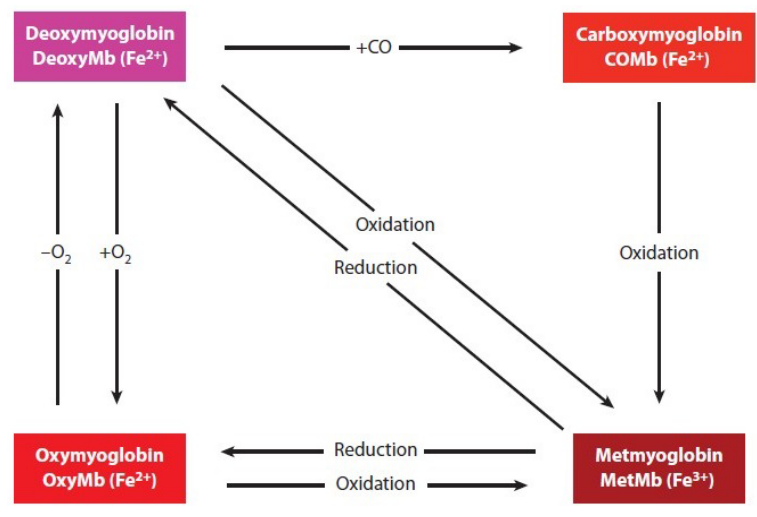

Figure 1: Myoglobin redox forms in fresh meats [4].

Flow Chart for Reduced Myoglobin to Oxymyoglobin to Metmyoglobin Formation

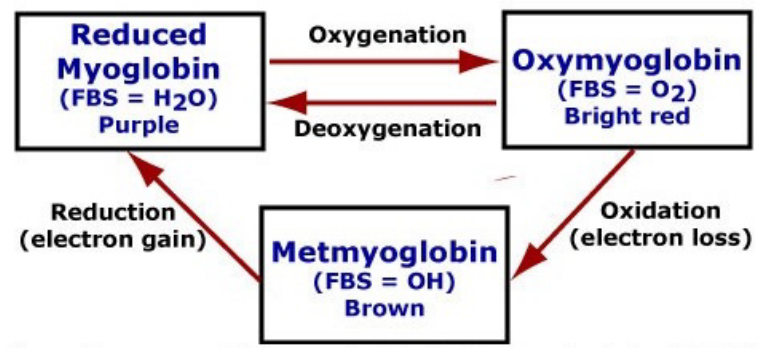

Figure 2: Metmyoglobin reducing activity (MRA).

\section{Meat color and meat product colorants status and development trend}

Nitroso-hemoglobin prepared by use of by-products (beef blood), $(\mathrm{Hb})$ preparation condition as modified starch and maltodextrin were taken as raw materials, color fixative was microencapsulated and spray dried reacting with nitrogen monoxidum on definite condition and its application prospect substitutes of nitrite in meet's product from color fixative, antioxidant, antimicrobials, increase nutrition value, and introduced as additives. Additionally, to make meat color fixative with good stability and coloring ability nitroso-hemoglobin pigment synthesis. Moreover, economic aids and environmental protection.

\section{Meat color}

Color of meat known as myoglobin proteins, and it's recognized in exudation by gel-electrophoresis, fully accounting in part for the modification on the pigment steadiness of meat after chilling conditions and melting $[19,20]$. The denaturation guidance's to an improved sensitivity of myoglobin to auto-oxidation and following diminution of optimum color production. This model possesses existed confirmed by various writers by associating the grade of bloom and the capability of the meat to resisting oxidization to metmyoglobin through cooled storehouse post freeze/thaw [21-25]. Moreover, previously it was reported that the denaturation of the globin moiety of the myoglobin molecule possesses the function at some stage through chilling, chilled storing and defrosting by Calvelo [26] (Table 1). Preparation of Molecularly imprinted polymer (MIP) was schemedin synthesis of molecularly imprinted polymer to the Au electrode surface through an electrode by $H b$ with (eATRP) both as catalytic agent and template [27]. Then the elect trade was injected to protein solution containing $A M, H b$, and $M B A$ as functioning electrode. When a potential was applied toreduce $\mathrm{Hb}-\mathrm{Fe}$ (III) to $\mathrm{Hb}-\mathrm{Fe}$ (II) catalyst for (eATRP), polymerization would be triggered. After the removal of $H b, M I P$ was efficaciously ready on the surface of the electrode $(M I P / A u)$ [27]. The functional monomer and cross-linker were acrylamide (AM) and N. N-methylene bis-acrylamide (MBA), respectively. In order to improve the polymer growth, mixed SAM of initiator and HTP was self- assembled on the surface of $\mathrm{Au}$ electrode $(\mathrm{Br} / \mathrm{Au})$ [27]. Reaction reversible dependent of enzyme's and the compounds (Figure 1). Alteration myoglobin oxymyoglobin vice usually, quiet, Likewise, reaction produces brown metmyoglobin quiet but reverse this more in meat, is dynamic in company oxygen three myoglobin, and is interconverted; three are evenness one (Figure 1). Moreover, meat chemistry pigments showed that the converted of myoglobin from a dark purple pigment to a brightred pigment merely from oxymyoglobin or to a brown pigment by losing electrons due to present of oxygen depending on the store situations the meat pigment's oxymyoglobin, metmyoglobin, and myoglobin, can be transformed from one to the other [4]. Oxymyoglobin and myoglobin they able to lose an electron (oxidation) changes the pigment 


\begin{tabular}{|l|l|}
\hline \multicolumn{1}{|c|}{ Title } & Results/Conclusion \\
\hline The Oxford Companion to Food. 2nd ed. UK: Oxford University Press, p. 81-82. & $\begin{array}{l}\text { Preparing a traditional dishes, it is made with meat, blood, and spices all encased } \\
\text { in the animal's entrails or intestinal in Kenya. }\end{array}$ \\
\hline The Oxford companion to food, OUP, p.104. & $\begin{array}{l}\text { Make black pudding generally made from pork blood mix with oatmeal, occasionally } \\
\text { flavored with pennyroyal, and barley instead of onions to absorption blood. And it is } \\
\text { ready to eat but is habitually grilled, and fried or boiled in its surface. }\end{array}$ \\
\hline Mutura - The traditional Kenyan sausage. On1 May 2014. & $\begin{array}{l}\text { Preparing traditional dish, it is made from meat blood, and spices all coated in the } \\
\text { animal's intestines or stomach (central of Kenya). }\end{array}$ \\
\hline $\begin{array}{l}\text { The Oxford Companion to Food. 2nd ed. UK: Oxford University Press, 2006, p. } \\
81-82 .\end{array}$ & $\begin{array}{l}\text { Used coagulated blood from (pig, duck, chicken, sheep, goat, and cow) as fried } \\
\text { food or steamed as snack food rectangular pieces and cooked is most often used } \\
\text { (In the Northeast China and Taiwan). }\end{array}$ \\
\hline Stick Out Your Tongue Chatto and Windus London. & $\begin{array}{l}\text { Used blood (enzyme's Hat takes part in blood clotting) as established required } \\
\text { agents and additional to meat cuts or minced meat to creation portions of looked-for } \\
\text { mass and formation. }\end{array}$ \\
\hline $\begin{array}{l}\text { Screening method for the addition of bovine blood-based binding agents to } \\
\text { food using liquid chromatography tripled quadrupole mass spectrometry. Rapid } \\
\text { Communications in Mass Spectrometry, 21(18): 2919-2925. }\end{array}$ & $\begin{array}{l}\text { Used blood as based binding agents and supplementary (increase nutrition value) } \\
\text { to minced meat or meat cuts to form portions of required mass and procedure in the } \\
\text { binding process, and thrombin cleaves fibrinogen }\end{array}$ \\
\hline
\end{tabular}

Table 2: Summary of research evaluating to use's blood as food or additives.

called denatured metmyoglobin is shaped, which normally cannot be transformed to another pigment. To preserving this color needs that the meat surface must be free from any pollution reason a chemical reaction subsequent in the metmyoglobin pigment Oxygen must be obtainable for an enough attentiveness in order to the association with the myoglobin to procedure oxymyoglobin $[4,28]$. This reaction is reversible and depends on the current of oxygen, active enzymes and decreasing compounds in the muscle (Figure 2). The procedure or operating system of cooking consequences in change in the protein composition of soluble myoglobin (denaturation), and temperature persuaded myoglobin denaturation is held directly accountable for the lethargic umber pigment of cooked meats [29]. Nitrite is commonly used in meat products, but it is a poisonous reagent, and can produce carcinogenic nitrosine after reacting with amine. So people are looking for new type of pigment beef blood instead of nitrite. Also, a valuable source of protein is missing if animal blood is cast off as leftover and this is led to serious environmental contamination troubles, there are several nations need that the animal blood be willing to in a biologically kindly method, which is a wealth concentrated procedure [14].

\section{Meat product colorants status and development}

Nitroso-hemoglobin prepared by use of by-products (beef blood), $\mathrm{Hb}$ ) preparation condition as modified starch and malt dextrin were taken as raw materials, color fixative was microencapsulated and spray dried reacting with nitrogen monoxidum on definite condition and its application prospect substitutes of nitrite in meet's product from color fixative, antioxidant, antimicrobials, increase nutrition value, and introduced as additives. Additionally, to make meat color fixative with good stability and coloring ability nitroso-hemoglobin pigment synthesis. Moreover, economic aids and environmental protection. A promising approach to improving meat color care would be to produce food supply as a preventive color care strategy. The food supply could be improved by producing functional foods that have nutritional profiles that are healthier than conventional products. However, production of functional foods is not always easily accomplished since they must also taste good, be convenient and reasonably priced so that consumers will regularly purchase and use the products [12].

\section{Hemoglobin profiles (source, structure and properties)}

Structure and function: Sadava [3] reported that hemoglobin tetramers are contained of the four subunits, two a-globin chains and two $\beta$-globin chains all of which take the form of alpha helices. Found in each chain is a non-protein heme group, which is an assembly of cyclic ring structures surrounding an iron ion that is tied by nitrogen atoms and the heme group are characteristically hidden within the several subunits, is covalently bound to yet dissimilar atom longs for a histidine and is a chain, with hydrophobic stabilize heme with in subunit. Molecules opposite the histidine. Near opposite is a different chain, serves significant even it not bound the group (Perultz, Histidine itself charged; close to negatively iron averts iron from too, which inhibit binding oxygen Heme has greater affinity carbon than oxygen, of chain histidine allow groups to bind to waste to prevent the proteins providing with oxygen for activities 2006). Of hemoglobins of transport, oxygen-bind $\mathrm{Fe}^{2+}$, not (Boyer, Also, size, and of the distal chain of molecules will to heme (Boyer, directly cutting, color quite-would a purplish-redtois (surface the blooms) this is oxymyoglobin, beef bright red associate freshness.

Hemoglobin utilization: To make attractive color using by consumers to judge meat freshness. Substitute of nitrite in the meat and meat products from colorant, antioxidant, and increase nutrition value. Enhance color changes, first converting to nitroso-myoglobin (bright red), then, on heating, change to nitroso-hemochrome (a pink pigment). Progress of nitroso-hemoglobin pigment synthesis and its application in meat product. Color is particularly an important quality guideline for both fresh meat and nitrite cured meat commodities and depends upon the oxidation-reduction status and ligand bound to heme iron in $\mathrm{Mb}$. The fundamental knowledge of Mb chemistry is therefore, crucial, and the "inorganic chemistry" of meat had to include a quantitative accurate description of $\mathrm{Mb}$ complicated formation with small ligands, such as $\mathrm{O}_{2}, \mathrm{NO}, \mathrm{H}_{2} \mathrm{O}$ and $\mathrm{CO}$, and the kinetics of transformations of these complexes under transforming conditions of temperature, oxygen pressure, $\mathrm{pH}$, ionic strength and light exposure. The practical aspect of colour solidity of meat and meat products in the meat industry and retail trade has started abundant examinations over the last 50 years and significantly an increased understanding of the complicated chemistry [30]. The detection of the physiological momentousness of $\mathrm{NO}$ and the quite possible function of hypervalent $\mathrm{Mb}$ and $\mathrm{Hb}$ throughout the oxidative stress possess added new perspectives to the dynamic description of electron transfer and ligand exchange reactions of these heme pigments [31]. Additional significant functions of $\mathrm{Mb}$ than oxygen conveyance and storage seem to be important, and these in vivo important functions contain activity as a pseudo-enzyme in quite specific muscle tissue similar to NO dioxygenase clearly recognized from microorganisms. In effect, $\mathrm{Mb}$ characterizes as a cellular defender against nitrosamine stress during excess production of NO [30]. Future investigation is supposed to focus on the role of $\mathrm{Mb}$ as a mediator of responses between small molecules most important as bio-regulators and contain researches of reaction dynamics hopefully happening within the protein structure using time-resolved spectroscopy [30]. 


\section{Title}

Comparison of color and thiobarbituric acid values of cooked hamburger patties afte storage of fresh beef chubs in modified atmospheres.

Internal premature browning in cooked steaks from enhanced beef round muscle packaged in high-oxygen and ultra-low oxygen modified atmospheres.

Effect of muscle source on premature browning in ground beef.

Effect of erythorbate, storage and high-oxygen packaging on premature browning in ground beef.

Effects of succinate and $\mathrm{pH}$ on cooked beef color.

Chitosan inhibits premature browning in ground beef.

Factors that influence cooked meat color. Journal of Food Science, 71, R31-R40.

\section{Results/ Conclusion}

High oxygen modified atmosphere packaging increases, while low oxygen and $0.4 \% \mathrm{CO}$ avoid early change to brown color in ground beef, use this technique in meat manufactures to avoid meat color.

The improved of beef round steak packaging in high oxygen modified atmosphere packaging (MAP) are brown when heated to $71.1^{\circ} \mathrm{C}$ for the high oxygen MAP encourages oxy-hemoglobin creation in the product.

Muscle basis position, and inherent biochemical that can be affected of shape ground of beef cooked color.

Addition of erythorbate to ground beef rises decreasing movement previous to cooking and reductions the incidence of premature browning color.

The effect of succinate is partially due to increase of $\mathrm{pH}$, and it can protect myoglobin against thermal denaturation, and ground beef enhanced cooked redness due to $\mathrm{pH}$.

Myoglobin's thermal constancy is dependent on several issues such as color concentration, myoglobin redox state, and muscle source, $\mathrm{pH}$, packing kind, storing condition, as well as adding ingredients.

The cooked of meat color due to the myoglobin denaturation, and thermal stability is dependent on myoglobin redox formal, muscle source, pigment concentration, $\mathrm{pH}$, packaging type, storage situation, and ingredients added.

Table 3: Summary of research assessing current affecting in meat product's color.

\section{Progress and functional of Nitroso-hemoglobin preparation}

Summary of investigation appraising to use's blood as food or additives was shown in Table 2. Numerous nations eat blood as diet, normally in mixture with meat used as supplementary (increase nutrition value) to form of blood sausage, as a thickener for sauces, a preserved salted form for times of diet lack, or used blood as the soup [31-35]. There is the traditional dish blood food among the people of dominant Kenya Mutura, it is made from mixing meat, blood, and spices all inside the animal's intestines or stomach. In United Kingdom produced black pudding usually made from ham blood and a comparatively in height prepared of oat flour in the previous it was sporadically flavored through pennyroyal, and different from continental European forms in its comparatively limited range of elements and dependence on oat flour and barley substitute of onions to absorption the blood, and it can be consumed uncooked, but is often grilled, fried or boiled in its skin [36]. In Asia, there were many people produce diet from solid animal blood and greatest of these kinds' diet of don't have been casing and might be careful a form of sliced sausage $[37,38]$. Although in Chinese cultures, as well as Taiwan whole coagulated blood is fried or steamed as a food or cooked in a hot jar and rectangular piece and cooked is most often made through pigs or duck's blood, chicken's, and cow's blood as well as used in the Northeast China, blood sausage is a traditional food which is cooked with goat or sheep blood in resource-poor, congealed yak's blood used as the traditional food in Tibet area [38]. Although used blood as additives and enzymes take part in blood coagulation these be able to be used as blood as binding agents and supplementary to meat slashes or minced meat to procedure portions of wanted mass and form in the binding method, thrombin cleaver's fibrinogen to fibrin peptides and used to detect bovine and porcine fibrin peptides concentrations down to 5\% [39]. As the fibrin peptides, species exact the approaches are capable of discerning amid blood-based binding agents of bovine and porcine origin. The nutrition blood of livestock and poultry is very rich, most of the hemoglobin; deposit lies in the red blood cells, accounting for $80 \%$ of the total protein. However, hemoglobin color and stability are very poor; the hemoglobin $(\mathrm{Hb})$ protein is made up of four molecules and molecules composed of four peptides globulin, and muscle of myoglobin $(\mathrm{Mb})$ is composed of a molecule hemoglobin and a molecule of a single polypeptide chain globulin [40,41]. Animals are used as food either directly as meat, which comes from muscle systems or from tissues or indirectly includes milk produced via mammary glands, in numerous cultures is drunk or treated into dairy products such as yoghurts, butter, cheese, etc., [36]. Additionally, some cultures are eating blood forming of blood sausage, as a thickener for sauces, or in a cured, salted form times of food lack in the sometimes, also use blood in stews such as jugged hare birds and other animals lay eggs, which are often taken as food, and bees produce honey, a reduced nectar from flowers, which is use a widespread sweetener in many cultures $[36,42]$. The increase used of modified atmosphere packaging has carried about some modifications in heated meat pigment (Table 3 ) owing the consequence of packaging atmosphere on myoglobin chemical reaction (redox), known as principal factor of heated pigment. Seyfert et al. [43] they reported that packaging of the beef steaks in high oxygen MAP greater than before and heightened prevalence color thoroughly heats excessively low to kill pathogen bacteria. Exactly, injection-enhanced beef in MAP was prematurely brown col while heated to $71.1 \mathrm{Co}$, a high temperature that ought to have some pink pigment and be inoffensive to consumption and strong degrees' oxygen in this product exploited oxymyoglobin creation on the surface and in certain carrying cases, deep inside the product [43]. Whereas MAP was an advantage for fresh meat pigment, it disposed culinary to produce products to early browning color at temperatures less than that compulsory for protection of diet, since oxymyoglobin and metmyoglobin were more temperature labile than deoxyhemoglobin and carboxymyoglobin [42]. Additional reasons affecting cooked pigment contain, source of muscle, anatomical situation, and inherent biochemical shape, fat contented, store at a low temperature, endpoint temperature of frozen storage, and post-cooking heat increase [44]. Myoglobin denaturation resulting creation of each ferro-/ferrihemochrome. Though, myoglobin's thermal solidity is dependent on different issues for example myoglobin redox state, muscle sources, $\mathrm{pH}$, storage condition, coloring concentration, added ingredients, and the type of packaging [29]. It expressly granted the function of myoglobin's oxidation-reduction state-run into heated pigment [42]. Obviously established that (CO) in improved atmospheres would carefully avoid early browning pigment of surface beef pies. Moreover, Suman et al. [45] recommended that erythorbate possibly will be commonly used to reduce premature browning. Metmyoglobin reducing activity, $\mathrm{pH}$ can keep myoglobin in contradiction of thermal denaturation the adding of succinate to grind beef enhance cooked red color the consequence of succinate is partly suitable 


\section{Title}

Changes in Color and Myoglobin of Minced Beef Meat Due to High Pressur Processing. Lebensm.-Wiss. u.-Technol., 28, (1995), 528-538.

Effects of carbon monoxide-modified atmosphere packaging and irradiation on $\mathrm{E}$. coli K12 survival and raw beef quality. Meat Science 83 (2009) 358-365

\section{Results/Conclusion}

The packet of red meat under vacuum power present of an oxygen scavenger in partially adequately meet color, and color values increased significantly.

Aerobic packed beef was optically greener and reduced redder than carbon monoxide (CO) in heavily atmosphere packaging CO-MAP, and sufficient preserved and provide color. However, storage period was the main factor lead to reducing fresh beef and substantially increasing or considerably acid green and rancid odor.

Evaluation of carbon monoxide treatment in Modified atmosphere packaging or Packaging or Vacuum packaging method is excessively important to development of vacuum packaging to increase color stability of fresh beef Meat Science 59 (2001). raw beef color needed to maintain redness and extended color stability and decrease 317-324. of microbial counts.

Carbon monoxide in modified atmosphere packaging affects color, shelf life, and It determined that the use of $0.4 \%$ carbon monoxide (CO) through an ultra-low oxygen microorganisms of beef steaks and ground beef. Journal of Food Science, 69(1), pack had to enhance the beef color immovability deprived of hiding decomposition and C45-C52 biochemical profile of muscle may result from reaction to (CO).

Evaluation of carbon monoxide treatment in modified atmosphere packaging or The usage of $0.5 \%$ carbon monoxide, and $0.5 \%$ (CO-MAP) system with pretreating vacuum packaging to increase color stability of fresh beef. Meat Science, 59(3), steaks can increase color stability through following vacuum packaging and 317-324. significantly economic aid.

Table 4: Summary of research evaluating changes in Color and myoglobin effect atmosphere packaging

Title

\section{Results/Conclusion}

Formation of red myoglobin derivatives and inhibition of spoilage bacteria in Myoglobin derivatives by bacteria such us (Staphylococcus xylosus and Lactobacillus raw meat batters by lactic acid bacteria and Staphylococcus xylosusLWT - fermentum) using as substitution of nitrite and significantly progressing meat pigment and Food Science and Technology 68 (2016) 251-257.

Production of cured meat color in nitrite-free Harbin red sausage by The Lactobacillus fermented was capable of producing NO-Mb in this sausage product

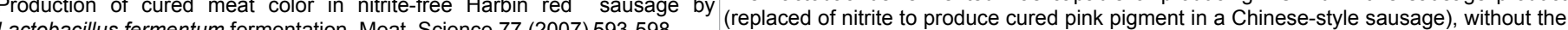
Lactobacillus fermentum fermentation. Meat Science 77 (2007) 593-598.

Elucidation of the chemical structure of preformed cooked cured-meat pigment by electron paramagnetic resonance spectroscopy. Journal of Agriculture and Food Chemistry, 44 (1996) 416-421.

Color structure in fermented sausages by meat-associated staphylococci with Staphylococcus strains in nitrite-cured sausages were of partial significance highly various nitrite- and nitrate-reductase activities. Meat Science 78 (2008) 492-501. regarding color improvement, and color formation through initial fermentation stages.

Influence of high pressure on the color and microbial quality of beef meat. Lebensm.-Wiss. u.-Technol. 36 (2003) 625-631.

The valuation immediate effect of varying pressure values (50-600 MPa) and holding times (20-300S) on color improvement and microbiological quality of meat product (bovine muscle).

\begin{tabular}{l|l} 
Synthesis process and application of nitroso hemoglobin in sausage & The use of $(\mathrm{HbNo})$ as color additive and replace NaNo2 or NaNo3 in meat products like
\end{tabular} decreased residues.

Table 5: Summaries evaluating research of antimicrobial significantly affecting meat product color.

to significantly increased PH [46]. Moreover John et al. [42] and Suman et al. [47] report that the vacuum packaging beef devoid of oxygen (vacuum or CO-MAP) be able to efficiently the reduction of the incidence of early browning. The changes in Color effect atmosphere packaging (Table 4) minced beef meat was packed under vacuum power, air or oxygen; pigment great rates enhanced in the range the meat virtual becoming pink, whereas values significantly decreased the meat becoming grey-brown. Concomitantly, total extractible myoglobin reduced, at the same time as the quantity of metmyoglobin substantially enhanced at the write-off oxymyoglobin pressurization did not meaningfully raise the extractability of heme iron by an acid solution and meat packaging under vacuum in the company of an oxygen scavenger somewhat supported meat color [48]. Furthermore, color changes resultant from pressure handling are caused by two or three diverse mechanisms. In the attendance of nitrite, the extensive nitrosomyoglobin is defended against oxidization into the ferric form. The whitening consequence, however, is not hampered [49]. Vacuum packaging (VP) is excessively important new approaches to increase raw beef red pigment steadiness for carbon monoxide (CO)-treated beef steaks was wanted to take care of ruddiness succeeding repackaging in (VP). Extended color relative stability lows of microbial counts in (VP) was successfully achieved by pretreatment with $5 \% \mathrm{CO}$ [50]. Combined effects of irradiation and (CO) in modified atmosphere packaging (CO-MAP) on total plate counts, Escherichia coli K12, color, and odor of fresh beef through the cooled store. Aerobically or in COMAP, no substantial difference existed for visual green color scores due to gas atmosphere aerobically packaged beef was greener and less red than CO-MAP packaged beef and reduced microbic loads to protected levels through 28 days of storage. Red color of CO-MAP packaged samples significantly decreased slightly after irradiation [49]. The application of $0.4 \%(\mathrm{CO})$ through the store period in MAP enhanced the beef pigment without effectively masking spoiling upon removal of end product from (COP), meat pigment grouping of $\mathrm{COMb}$ and $\mathrm{OMb}$ ) deterioration through the demonstration as a method not different as of produce the product exposed only to air [51]. Furthermore, upon take product from (COP), meat pigment the combination of $\mathrm{COMb}$ and $\mathrm{OMb}$ declined through presentation in a manner not distinctive from product quite increasingly exposed only to air [50]. They are Theyrted that the usage of packing steaks and surface beef in $0.5 \%(\mathrm{CO})$ leads to better-quality color constancy. While usage of a (COP) system that also contained oxygen prohibiting, and low levels of (CO) tested [50,51]. The evaluating research of antimicrobial meaningfully affecting meat color (Table 5). Effectively a probable efficient method for nitrite substitution by considerably improving meat pigment and preventing microorganism spoiling in meat miraculously curing by using the change of metmyoglobin (MbFeIII) to red myoglobin derivatives by micro-organisms such as Staphylococcus xylosus and Lactobacillus fermentum and their positive influence on the major impediment of spoilage organisms in crude meat batters as essentially defensive cultures fully investigate dependent and independent culture (PCRdenaturing gradient gel electrophoresis) implement approaches were functioning in disclose the microbic generation [52]. Moreover, $L$. fermentum creative ferment donated to the structure of $\mathrm{NO}-\mathrm{Mb}$ in cured meat deprived of the adding nitrite was financed by the lack of 


\section{Title}

The potential of increased meat intake to improve iron nutrition in rural Kenyan school children. International Journal for Vitamin and Nutrition Research, 77(3), 193-198.

Meat, fish and fat intake in relation to subsite-specific risk of colorectal cancer: The Fukuoka Colorectal Cancer Study. Cancer Science, $98(4)$, 590-597.

Food, nutrition, physical activity, and the prevention of cancer: A global The majors increase of considerable alarms approximately the cancer risks correlated with perspective. Washington, DC: American Institute for Cancer Research.

Meat and meat mutagens and risk of prostate cancer in the agricultural health study. Cancer Epidemiology, Biomarkers and Prevention, 17(1), 80-87.

"Healthier meat products as functional foods." Meat science 86(1): 49-55.

\section{Results/Conclusion}

isk associated with treated meat's consumption accompanied by other significant risk matters connected with colorectal cancer, micro-nutrients such as zinc, iron and vitamins.

The measurement of colorectal cancer occurrence was not found to be directly connected to

\section{consumption of red and processed meats.}

The consumption of well or very well done total meat was accompanying accompanied by advanced disease were of borderline significance for increased prostate cancer risk.

Healthiness care possibly will be proactively considerably improved by manufacturing a in good health food provide as a preventative healthiness care strategy and food security classification through both positive and negative nutritionarycharacteristics. meet or treated meat product's intake in a Japanese limited population.

Table 6: Summaries of research evaluating processed meat and colorectal cancer.

any quantifiable rosy pigment if the sausage was handled with neither supplemented nitrite nor $L$. fermentum, and the suggested that the $L$. fermentum implementation level was particularly important; a 108 $\mathrm{CFU} / \mathrm{g}$ vaccination was strictly necessary to produce the pink color high intensity comparable to that produced by $60 \mathrm{mg} / \mathrm{kg}$ of nitrite [53]. Using of nitrosylmyoglobin, with proper antioxidant, and antimicrobial agent to yield good substitute pink, cured pigment is settled to microbial transformation of myoglobin [54]. Nitrosylated hemin has been technologically advanced for nitrite-free cured meats. When presynthesized nitrosyl myoglobin, with accepted antioxidant, and antimicrobic agents, were supplemented to fresh meat, the eventually consequent meat productions reportedly resembled nitrite-cured meats [54]. Staphylococcus strains, such as (S. carnosus, S. simulans and S. saprophyticus), chosen due to their highy variable nitrite and/or nitratereductase activities, were used to formally initiate pigment formation during sausage ferment the rate of nitrosyl myoglobin formation in sausages through additional of nitrate depended on the limited specific Staphylococcus, high strain nitrate-reductase activity showed a faster rate of pigment development of product stability for the sliced, packed up sausage was fully assessed as surface pigment and oxidization by auto fluorescence and hexane content [55]. Presentation of record high intensity of pressure for a short period dominances to a substantial reduction of total flora quickly growing in meat product a delay of one week; this delay pre-eminences to let the ripening of the meat longer, and perhaps will be improving the meat tenderness. Though, this intensity of pressure is not perfectly adequate to change the microbiology of beef meat, therefore, a select basic essentials continually be possessed among a color development and a microbiological enhancement hinging on the final meat product formed exploitation development though, this advantageous good result of the act is attended by a splotch of meat [56]. The influence of pressure is larger substantial than that of the retention period on the pigment factors and metmyoglobin content. The pressures $(130 \mathrm{MPa})$ reason an enhancement in meat pigment quality with and significantly increase in ruddiness whatever is preserved through several days of the storage period. Indeed, $130 \mathrm{MPa}$ resolve be preferred to sell raw meat and meat products [56]. The using of nitroso-hemoglobin with monascus colors lade to reduce the total plate counts, ability to improve the presence and quality of red sausage, and nitroso-hemoglobin used as instead of sodium nitrite in the application of sausage, furthermore, use of nitroso-hemoglobin to replace the amount of residual nitrite meat products, significantly improve the security of the sausage [57].

Grillenberger et al. [58] mentioned that dissimilarity the stages of intake related to and raised hazard for increasing cancer in the company of the degrees essential to source micro-nutrients such as (zinc, iron and vitamins). Exhibition that the new development in meat product's consumption in Japan and Korea as considered the colorectal cancer rate was not found to be associated to meet product or processed meat intake in a Japanese limited population-based case-control study 782 cases and 793 controls [59]. Furthermore, Koutros et al. [60], the publication in 2007 of the elevated abundant alarms about the cancer risks correlated with red and processed meats, in determining that they are an utterly convincing cause of colorectal cancer (CRC) people ought to be the consuming further-up limit of $500 \mathrm{~g}$ of cooked red meat per week, and narrowly averting processed meats (Table 6). The majority of the present indication of hazard from such organic compounds depends upon close association of cancer risk with particular in good health cooked meats, likely to have high carcinogenic heterocyclic amines HCA degrees prospectively examined the association between meat types; meat cookery approaches meat doneness, and meat mutagens and the risk for prostate cancer in 197,017 person-years of follow-up in the Agricultural Health care [61]. Constitution may well be proactively better-quality by industrial manufacturing a healthier food supply as a protective health-care policy and food classification with both positive and negative nutritionary characteristics [12] reported that every year, in the united states medicinal payments for great chronic diseases, including cardiovascular disease, cancer, osteoporosis, diabetes and obesity, spend to exceed 400 billion dollars, lots of these disorders are commonly known to be directly linked to the human diet that is meant that many challenges in health care could be proactively enhanced by producing a healthier food supply as a preventive healthcare policy.

\section{Conclusion and Future Prospects}

Meat systems have a great potential for delivering important nutrients into the diet. Significant fresh meat color research has been shown in the last few years; Nitroso-hemoglobin prepared to use byproduct's beef (blood) extracting hemoglobin from blood processing, and its application prospect were the expounded substitutes of nitrite in meat product from color fixative, color ability and stability, antioxidant, antimicrobials and increase nutrition value and introduced as additives. Prospective research study might make use of health systems and implementations to perform significantly advances in our knowledge of meat color constancy compared to our current, more applied product research.

\section{Acknowledgement}

I wish to express my special appreciations and gratitude to my supervisor Prof. Meihu Ma, and Prof. Guofeng Jin for their helpful supervision proper guidance patience, kindness, attitudes, advices and encouragement to carry out this work. I am very much indebted to china government scholarship. Special thanks are due to all my friends for their assistance and encouragement. 
Citation: Hammad HHM, Meihu M, Guofeng J, Lichao H (2017) Nitroso-Hemoglobin Preparation and Meat Product Colorant Development. J Food Process Technol 8: 658. doi: 10.4172/2157-7110.1000658

\section{References}

1. Benfatto DM (2006) A combined computational and experimental approach in the structural investigations of metalloproteins.

2. Corbett SA, Foty RA (2008) Cell structure, function, and genetics, in surgery. Springer pp: 37-73.

3. Sadava DE (2008) Understanding genetics: DNA, genes, and their real-world applications. Teaching company.

4. Mancini R, Hunt M (2005) Current research in meat color. Meat sci 71: 100-121

5. Herrero AM (2008) Raman spectroscopy a promising technique for quality assessment of meat and fish: A review. Food Chem 107: 1642-1651.

6. Carpenter CE, Cornforth DP, Whittier D (2001) Consumer preferences for beef color and packaging did not affect eating satisfaction. Meat Sci 57: 359-363.

7. Krystallis A, Chryssohoidis G (2005) Consumers' willingness to pay for organic food: Factors that affect it and variation per organic product type. British Food J 107: 320-343.

8. Bredahl L (2004) Cue utilisation and quality perception with regard to branded beef. Food Qual Pref 15: 65-75

9. Boles JA, Pegg R (2010) Meat color, Montana State University and Saskatchewan Food Product Innovation, Program University of Saskatchewan.

10. Reilly C (2008) Metal contamination of food: Its significance for food quality and human health. John Wiley \& Sons, USA.

11. Mc Clements DJ, Decker EA, Park Y, Weiss J (2009) Structural design principles for delivery of bioactive components in nutraceuticals and functional foods. Critical Rev Food Sci Nutri 49: 577-606.

12. Decker EA, Park Y (2010) Healthier meat products as functional foods. Meat Sci 86: 49-55.

13. Swapna CH, Amit KR, Vinod KM, Bhaskar N (2012) Characteristics and consumer acceptance of healthier meat and meat product formulations - A review. J Food Sci Technol 49: 653-664.

14. Ofori JA, Hsieh HA (2012) The use of blood and derived products as food additives. INTECH Open Access Publisher.

15. Koemseang S (2015) The Improving stability of hemoglobin-based natural food colorant by means encapsulation with calcium alginate.

16. Fu-Man Y, Hong-Zhan Y, Wu-Bian J, Yu-ming C, Jin-Feng L (2011) A review on applications of intensively processed pig blood products in meat products. Meat Res 7: 9-15.

17. Mohan A (2009) Myoglobin redox form stabilization: Role of metabolic intermediates and NIR detection. Kansas State University.

18. Zhang $\mathrm{H}$, Kong B, Jiang $\mathrm{Y}$ (2012) Development and application of the substitute of nitrite in the meat product. Packag Food Machine 3: 16.

19. Paredi G, Sentandreu MA, Mozzarelli A, Fadda S, Hollung K, et al. (2013) Muscle and meat: New horizons and applications for proteomics on a farm to fork perspective. J Proteomics 88: 58-82.

20. Han J (2008) The effect of pre-rigor infusion of lamb with kiwifruit juice on meat quality. Lincoln University.

21. Ben-Abdallah M, Marchello JA, Ahmad HA (1999) Effect of freezing and microbial growth on myoglobin derivatives of beef. J Agricultur Food Chem 47: 4093-4099.

22. Lanari M, Zaritzky N (1991) Effect of packaging and frozen storage temperature on beef pigments. Int J Food Sci Technol 26: 629-640.

23. Leygonie C, Britz TJ, Hoffman TC (2011) Oxidative stability of previously frozen ostrich Muscularis iliofibularis packaged under different modified atmospheric conditions. Int J Food Sci Technol 46: 1171-1178.

24. Marriottz NJ, Garcia RA, Kurlan ME, Lee DR (1980) Appearance and microbia quality of thawed retail cuts of beef, pork and lamb. J Food Protect 43: 185-189.

25. Otremba M, Dikeman M, Boyle E (1999) Refrigerated shelf life of vacuumpackaged, previously frozen ostrich meat. Meat Sci 52: 279-283.

26. Calvelo A (1981) Recent studies on meat freezing. Development Meat Sci

27. Sun $Y$, Du H, Lan Y, Wang W, Liang Y, et al. (2016) Preparation of haemoglobin $(\mathrm{Hb})$ imprinted polymer by $\mathrm{Hb}$ catalyzed eATRP and its application in biosensor. Biosensor Bioelectronic 77: 894-900.
28. Drăghici O, Avram I, Hîrîciu D, Nan M, Toader A, et al. (2013) Study on the beef pigments. Acta Universitatis Cibiniensis, Series E: Food Technol 17: 47-52.

29. Whyte R (2006) Does it look cooked? A review of factors that influence cooked meat color. J Food Sci 71: 31-40.

30. Møller JK, Skibsted LH (2006) Myoglobins: The link between discoloration and lipid oxidation in muscle and meat. Quimica Nova.

31. Shimizu T, Huang D, Yan F, Stranava M, Bartosova M, et al. (2015) Gaseous $\mathrm{O}_{2}, \mathrm{NO}$, and $\mathrm{CO}$ in signal transduction: Structure and function relationships of heme-based gas sensors and heme-redox sensors. Chemical reviews 115 6491-6533.

32. Lei C (2013) Research progress of new type pigment glycosylated nitrosohemoglobin. J Anhui Agricultur Sci 7: 120

33. Han K, Bao-hua K, Qian L (2012) Influence of nitrosohaemoglobin with monascus on the colour and quality of red sausages. Sci Technol Food Industry 8: 21

34. Fei L, Xin S, Rui-Yao H, Xin-Xin Z (2014) The research progress of nitrosohemoglobin pigment synthesis and its application. China Food Additive 5: 027

35. Jawaid M (2013) Zabiha or halal meat?

36. Davidson A, Jaine T (2006) The oxford companion to food, segunda. Oxford University Press

37. Aoma I (2014) Development of frankfurter sausage using spider plant as an alternative filler and extender. University of Nairobi.

38. Ma J (2007) Stick out your tongue. Random House Publishing.

39. Helen HG, Reece P, Mark DS, Julie AC, Audsley N, et al. (2008) Method to screen for the addition of porcine blood-based binding products to foods using liquid chromatography/triple quadrupole mass spectrometry. Rapid Communication Mass Spectrometry 22: 2006-2008.

40. Andago AA (2015) Improving the iron status of children in Kisumu county Kenya using porridge flour enriched with bovine blood. University of Nairobi.

41. Pazos M, Medina I (2013) Oxidants occurring in food systems. Food oxidants and antioxidants: Chemical, biological and functional properties.

42. John L, Cornforth D, Carpenter CE, Sorheim O, Pettee BC, et al. (2004) Comparison of color and thiobarbituric acid values of cooked hamburger patties after storage of fresh beef chubs in modified atmospheres. J Food Sci 69: 608-614

43. Seyfert M, Hunt MC, Mancini RA, Kropf DH, Stroda SL, et al. (2004) Interna premature browning in cooked steaks from enhanced beef round muscles packaged in high-oxygen and ultra-low oxygen modified atmospheres. J Food Sci 69: 142-146.

44. Suman SP, Faustman C, Lee S, Tang J, Sepe HA, et al. (2004) Effect of muscle source on premature browning in ground beef. Meat Sci 68: 457-461.

45. Suman SP, Faustman C, Lee S, Tang J, Sepe HA, et al. (2005) Effect of erythorbate, storage and high-oxygen packaging on premature browning in ground beef. Meat Sci 69: 363-369.

46. Ramanathan R, Mancini RA, Dady GA, Van Buiten CB (2013) Effects of succinate and $\mathrm{pH}$ on cooked beef color. Meat Sci 93: 888-892.

47. Suman SP, Mancini RA, Joseph P, Ramanathan R, Konda MK, et al. (2011) Chitosan inhibits premature browning in ground beef. Meat Sci 88: 512-516.

48. Carlez A, Veciana-Nogues T, Cheftel JC (1995) Changes in colour and myoglobin of minced beef meat due to high pressure processing. LWT-Food Sci Technol 28: 528-538.

49. Ramamoorthi L, Toshkov S, Brewer M (2009) Effects of carbon monoxidemodified atmosphere packaging and irradiation on E. coli $\mathrm{K} 12$ survival and raw beef quality. Meat Sci 83: 358-365.

50. Jayasingh P, Cornforth DP, Carpenter CE, Whittier D (2001) Evaluation of carbon monoxide treatment in modified atmosphere packaging or vacuum packaging to increase color stability of fresh beef. Meat Sci 59: 317-324.

51. Hunt MC, Mancini RA, Hachmeister KA, Kropf DH, Merriman M, et al. (2004) Carbon monoxide in modified atmosphere packaging affects color, shelf life, and microorganisms of beef steaks and ground beef. J Food Sci 69: 45-52.

52. Li P, Luob H, Baohua KC, Qian LC, Chen C, et al. (2016) Formation of red myoglobin derivatives and inhibition of spoilage bacteria in raw meat batters 
Citation: Hammad HHM, Meihu M, Guofeng J, Lichao H (2017) Nitroso-Hemoglobin Preparation and Meat Product Colorant Development. J Food Process Technol 8: 658. doi: 10.4172/2157-7110.1000658

by lactic acid bacteria and Staphylococcus xylosus. LWT-Food Sci Technol 68: $251-257$

53. Zhang X, Kong B, Xiong YL (2007) Production of cured meat color in nitritefree Harbin red sausage by Lactobacillus fermentum fermentation. Meat Sci 77: $593-598$

54. Ronald BP, Shahidi F, Niall JG, Sheila ID (1996) Elucidation of the chemical structure of preformed cooked cured-meat pigment by electron paramagnetic resonance spectroscopy. J Agri Food Chem 44: 416-421.

55. Gøtterup J, Olsen K, Knöchel S, Tjener K, Stahnke LH, et al. (2007) Relationship between nitrate/nitrite reductase activities in meat associated staphylococci and nitrosylmyoglobin formation in a cured meat model system. Int J Food Microbiol 120: 303-310.

56. Jung S, Ghoul M, Lamballerie-Anton M (2003) Influence of high pressure on the color and microbial quality of beef meat. LWT-Food Sci Technol 36: 625-631.
57. Meihu M (2001) Studies on synthesis of $\mathrm{HbNO}$ and its application to reducing residual $\mathrm{NO}_{2}$ in sausages. Food Sci 8: 17 .

58. Grillenberger M, Murphy SP, Neumann CG, Bwibo NO, Verhoef H, et al. (2007) The potential of increased meat intake to improve iron nutrition in rural Kenyan school children. Int J Vitamin Nutri Res 77: 193-198.

59. Kimura Y, Kono S, Toyomura K, Nagano J, Mizoue T, et al. (2007) Meat, fish and fat intake in relation to subsite-specific risk of colorectal cancer: The Fukuoka Colorectal Cancer Study. Cancer Sci 98: 590-597.

60. Fund WCR (2007) Research, food, nutrition, physical activity, and the prevention of cancer: A global perspective. Amer Inst for Cancer Res.

61. Koutros S, Amanda JC, Dale PS, Jane AH, Xiaomei M, et al. (2007) Meat and meat mutagens and risk of prostate cancer in the Agricultural Health Study cohort. Cancer Res 67: 858-859. 